\title{
Learning styles of physiotherapy students and teaching styles of their lecturers in undergraduate gross anatomy education
}

\author{
D A Shead ${ }^{1,2} \mathrm{MSc}$ Physiotherapy; R Roos, ${ }^{1} \mathrm{PhD}$; B Olivier, ${ }^{1} \mathrm{PhD}$; A O Ihunwo, ${ }^{2} \mathrm{PhD}$ \\ ${ }^{1}$ Department of Physiotherapy, Faculty of Health Sciences, University of the Witwatersrand, Johannesburg, South Africa \\ ${ }^{2}$ School of Anatomical Sciences, Faculty of Health Sciences, University of the Witwatersrand, Johannesburg, South Africa
}

Corresponding author: D A Shead (dots@icon.co.za)

\begin{abstract}
Background. Anatomy is essential to prepare physiotherapy students for future clinical practice. Student learning styles and lecturer teaching styles may influence learning outcomes.

Objective. To determine if the learning style of this student population is consistent and compatible with lecturers' teaching styles for better learning outcomes. Methods. A descriptive cross-sectional study was undertaken during 2015 and 2016. The Grasha-Riechmann learning style scale (GRLSS) and GrashaRiechmann teaching style scale (GRTSS) were used to measure learning styles of two consecutive physiotherapy student cohorts and teaching styles of their anatomy lecturers, respectively.

Results. Student samples were small (group 1: $N=59$ and group 2: $N=54$ ), but response rates high $(n=39 ; 66.1 \%$ and $n=43 ; 81.5 \%)$ in 2015 and 2016 , respectively. Mean Likert scores for GRLSS indicated that the most popular choice for learning style was the dependent style (mean (standard deviation) $3.81(0.75))$ for group 1 and the independent style $(3.68(0.61))$ for group 2. Female students preferred the dependent style (group 1: $n=12 ; 30.8 \%$ and group 2: $n=10 ; 23.3 \%$ ) and male students the participant style (group $2: n=6 ; 14 \%$ ) of learning. Lecturers scored highest in the expert category of teaching styles. Compatibility between learning and teaching styles was seen in both years based on comparisons made using teaching style clusters, where the identified GRLSS and GRTSS were grouped together and seen to fit into specific cluster categories.

Conclusion. Consistency in learning style choice was observed. A degree of cohesion between student learning styles and their respective lecturers' teaching styles augured well for good interaction between staff and students.
\end{abstract}

Afr J Health Professions Educ 2018;10(4):228-234. DOI:10.7196/AJHPE.2018.v10i4.1070

Anatomical knowledge is essential to the competency of physiotherapists in professional practice. ${ }^{[1]}$ Therefore, the way in which physiotherapy students learn gross anatomy has a bearing on their clinical acumen.

An abundance of literature on learning style models has been promulgated from the 1960s to date. Diverse opinion as to the value of learning style research is apparent. Early researchers were positively disposed to the idea of the educational value of knowing learning styles ${ }^{[2-4]}$ and some still uphold that belief. ${ }^{[5]}$ Recently, researchers have been more sceptical about the scientific value of enhancing student academic performance and facilitating better teaching methodology in general, ${ }^{[6,7]}$ and in anatomy education in particular. $^{[8]}$

In 1978, Claxton and Ralston ${ }^{[2]}$ summed up a learning style as 'a student's consistent way of responding and using stimuli in the context of learning. Grasha and Yangarber-Hicks ${ }^{[9]}$ found that some learning styles are more dominant than others and some are only used if sufficient reason and support are given. ${ }^{[10]}$ It was found that the subject to be learnt could influence learning style preference, ${ }^{[11]}$ and health science students showed a preference towards a particular learning style..$^{[9]}$

In 1987, Curry ${ }^{[12]}$ described a learning style model depicted by an onionlike structure with four layers. These are from outside to innermost the 'instructional preference,' 'social interaction', 'information processing style' and 'cognitive personality style' layers. The Grasha-Riechmann learning style scale (GRLSS) was placed in the social interaction layer of that model and was aligned with the expectations of teachers and students and their interaction with the learning environment, as is the case in this study. ${ }^{[3,11,12]}$ Criteria that guided the choice of the GRLSS and Grasha-Riechmann teaching style scale (GRTSS) tools for data collection in this study were that the former was designed to collect information from university students. ${ }^{[4,13]}$ It exhibits compatibility with the GRTSS and thus facilitates easy comparisons between the two tools. The GRLSS has not been specifically negatively critiqued in the literature for its learning style preference stance.

This study forms part of a research project investigating various aspects of gross anatomy education for undergraduate physiotherapy students. It sought to identify any learning style preference trend peculiar to physiotherapy students and document the teaching styles of two consecutive cohorts of gross anatomy lecturers. The realisation that there was a paucity of specific pertinent information on these aspects of gross anatomy education necessitated the collection of the study data. It has been shown that age and gender significantly influence student learning style preference. ${ }^{[14]}$ This study aimed to assess how age and gender influence the learning style preferences of two chronologically consecutive student cohorts. All the information collected is factored into the research project and adds to the body of literature pertaining to the ongoing debate on the relevancy of using learning and teaching style measurement tools.

\section{Methods}

A descriptive cross-sectional design was used, with purposive sampling. The students invited to participate were second-year physiotherapy students in 
the gross anatomy classes of 2015 (student group 1: $N=59$ ) and 2016 (student group 2: $N=54$ ). The invited gross anatomy lecturers who taught the students were designated as lecturer group $1(N=5)$ and lecturer group $2(N=4)$. Ethical clearance was obtained from the Human Research Ethics Committee (ref. no. H15/04/12) of the University of the Witwatersrand, Johannesburg, South Africa. Permission was obtained from the university's dean of student affairs and the head of the Department of Physiotherapy to administer the survey to the student body. The standardised 60-question version of the GRLSS $^{[13]}$ was administered to student groups in September 2015 and late August 2016. To maintain confidentiality of participants, the GRLSS and demographic questionnaires were distributed and collected by the respective class representatives. No identifiers were on the answer sheets. Permission was obtained from the head of the School of Anatomical Sciences prior to distribution of the GRTSS to the lecturer groups. The standardised 40-question version of the GRTSS ${ }^{[15]}$ was distributed to and collected from the lecturer groups by the gross anatomy course coordinator for physiotherapy students. The timing of this distribution was aligned with that of the GRLSS to the student groups.

The standardised GRLSS ${ }^{[4,13]}$ administered to the student groups was evaluated for reliability by Baykul et al.: ${ }^{[16]}$ these authors found medium co-efficient scores for the six sub-categories. Internal consistency of each subscale was found to be acceptable and suitable for measuring interactive learning styles. ${ }^{[16]}$ The scoring sheet for the GRLSS includes information on learning style preference norm values according to specified age groups. ${ }^{[4]}$ These norms were formulated using Grasha's ${ }^{[15]}$ own research regarding learning styles, where he defined low, moderate and high 'cutpoints. He also defined the same levels for the GRTSS. ${ }^{[15]}$ The development of teaching style clusters by Grasha ${ }^{[15]}$ allowed for the matching of student learning style preferences with teaching style preferences for optimum transfer of knowledge from teacher to student. Data pertaining to validity or reliability of the GRTSS tool administered to the lecturers in the current study could not be found during a literature search. A 5-point Likert scale was used to score both scales. The sum of the scores in each category was divided to produce an overall score to one decimal place. Mean and standard deviation (SD) calculations were presented to two decimal places.
Descriptive data analysis was done using SPSS version 24 (IBM Corp., USA). Missing data were not replaced and therefore not included in the analysis. The 2015 and 2016 student cohorts' GRLSS data analysis results, including descriptive findings, are presented as means (SD), frequencies and percentages (Table 1). Results of Pearson's correlation coefficient and paired $t$-tests at $p<0.05$, comparing group means for differences and correlations between student groups 1 and 2, student group 1 and the GRLSS norms, and student group 2 and the GRLSS norms, are presented in Table 2. Calculations for the age groups 17-21 years and 22-28 years were done separately, as the GRLSS norms for each age group differed.

Figs 1 and 2 illustrate comparison of group means for each learning style by age category and their comparison with the associated GRLSS norms. Fig. 3 shows the relationship between gender and student learning style preference for student groups 1 and 2 .
The GRTSS rankings for teaching style choices made by both lecturer groups were calculated and tabulated as mean (SD) values (Table 3). Data analysis was undertaken to establish prevalent teaching styles and cluster categorisation of the two teaching cohorts for comparison with the student learning style preferences identified in each year studied.

\section{Results}

\section{Participants}

In 2015, the student group comprised 59 students and 39 (66.1\%) completed the GRLSS. In 2016, the student group consisted of 54 students and 43 (81.5\%) completed the GRLSS. Five lecturers taught the students in 2015 and all completed the GRTSS. In 2016, 4 lecturers taught the students and $3(75 \%)$ participated in the study.

Table 1 provides information regarding the demographic profile of student participants. The majority were 20 years of age (group 1: $n=18$; $46.2 \%$ and group $2: n=22 ; 51.2 \%$ ). In both groups,

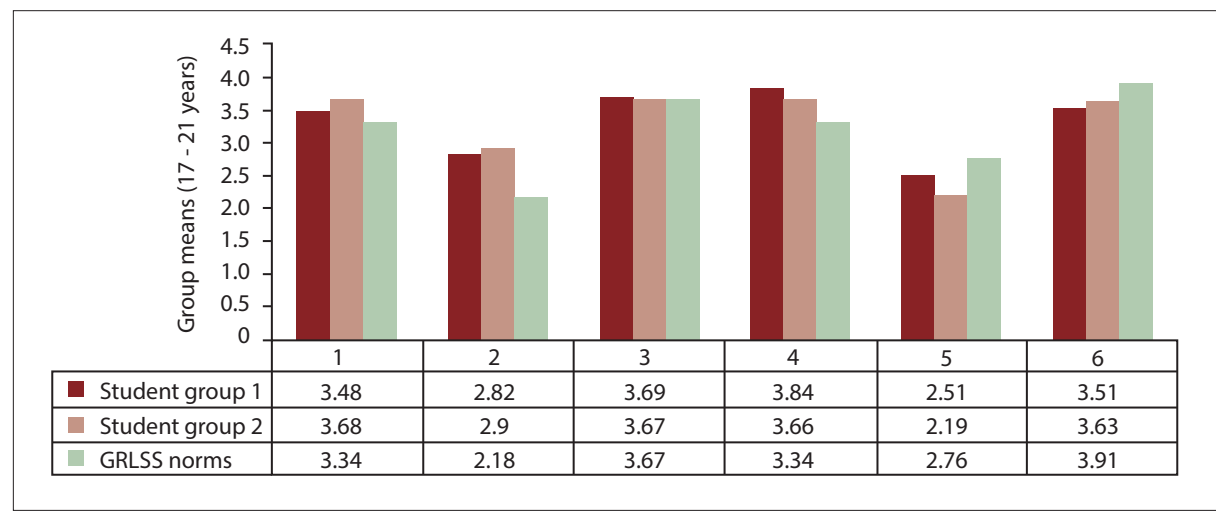

Fig. 1. Comparison of group means for Grasha-Riechmann learning styles (17 - 21 years) and Grasha-Riechmann norms for this age group. (GRLSS = Grasha-Riechmann learning style scale; $1=$ independent; 2 = avoidant; $3=$ collaborative $;=$ dependent $; 5=$ competitive; $6=$ participant .

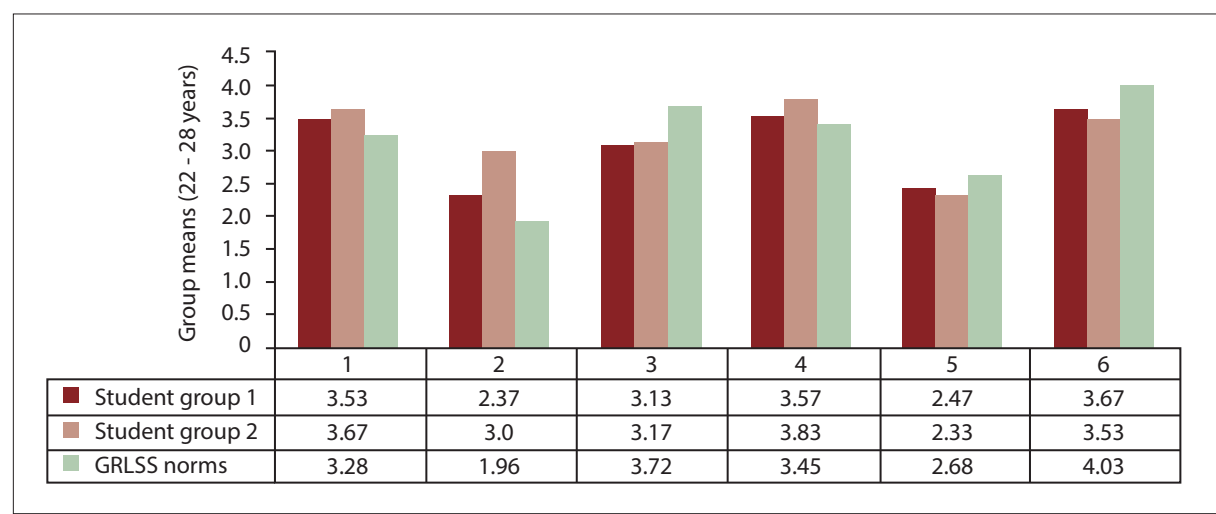

Fig. 2. Comparison of group means for Grasha-Riechmann learning styles (22 - 28 years) and Grasha-Riechmann norms for this age group. (GRLSS = Grasha-Riechmann learning style scale; 1 = independent; 2 = avoidant; 3 = collaborative; 4 = dependent 5 = competitive; 6 = participant . 


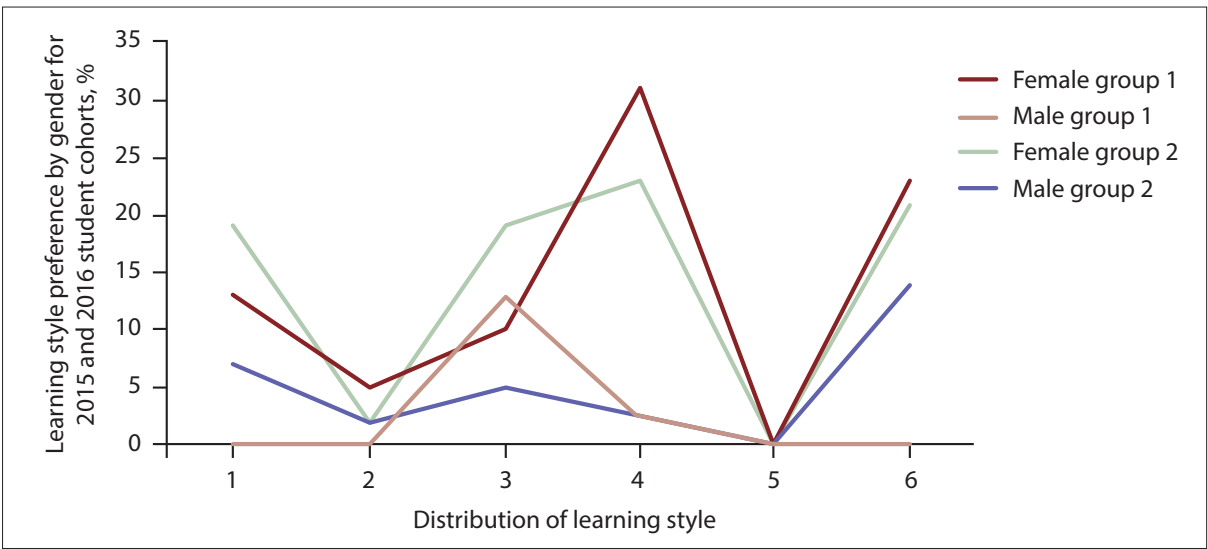

Fig. 3. Distribution of learning styles (1 - 6), by gender, for student groups 1 (2015) and 2 (2016); results are inclusive of age groups $(17-21$ years and $22-28$ years $) .(1=$ independent; 2 =avoidant; 3 = collaborative; $4=$ dependent $; 5=$ competitive 6 = participant . the number of female students was greater than that of male students (group 1 females: $n=32 ; 82.1 \%$ and males: $n=7 ; 17.9 \%$ ) (group 2 females: $n=33 ; 76.7 \%$ and males: $n=10 ; 23.3 \%)$. Pre-university education was predominantly private in group $1(n=24 ; 61.5 \%)$ and governmental in group $2(n=23 ; 53.5 \%)$.

\section{Learning style choices of student groups}

Table 1 provides information regarding the learning style of the student participants. Overall, the most popular learning style choice for student group 1 was the dependent style $(3.81(0.75))$ and for student group 2 the independent style (3.68 (0.61)). A student who chooses the dependent style is said to be passive, and needs structure

\begin{tabular}{|c|c|c|c|c|}
\hline \multirow{2}{*}{$\begin{array}{l}\text { Demographic information } \\
\text { Age (years), } n(\%)\end{array}$} & \multicolumn{2}{|l|}{ Group 1} & \multicolumn{2}{|l|}{ Group 2} \\
\hline & & & & \\
\hline 19 & \multicolumn{2}{|l|}{$4(10.2)$} & \multicolumn{2}{|l|}{$10(23.3)$} \\
\hline 20 & \multicolumn{2}{|l|}{$18(46.2)$} & \multicolumn{2}{|l|}{$22(51.2)$} \\
\hline 21 & \multicolumn{2}{|l|}{$14(35.9)$} & \multicolumn{2}{|l|}{$8(18.6)$} \\
\hline 22 & \multicolumn{2}{|l|}{$1(2.6)$} & \multicolumn{2}{|l|}{$1(2.3)$} \\
\hline 23 & \multicolumn{2}{|l|}{$1(2.6)$} & \multicolumn{2}{|l|}{$1(2.3)$} \\
\hline 24 & \multicolumn{2}{|l|}{$1(2.6)$} & \multicolumn{2}{|l|}{$1(2.3)$} \\
\hline \multicolumn{5}{|l|}{ Gender, $n(\%)$} \\
\hline Male & \multicolumn{2}{|l|}{$7(17.9)$} & \multicolumn{2}{|l|}{$10(23.3)$} \\
\hline Female & \multicolumn{2}{|l|}{$32(82.1)$} & \multicolumn{2}{|l|}{$33(76.7)$} \\
\hline \multicolumn{5}{|l|}{ Type of school, $n(\%)$} \\
\hline Government & \multicolumn{2}{|l|}{$15(38.5)$} & \multicolumn{2}{|l|}{$23(53.5)$} \\
\hline Private & \multicolumn{2}{|l|}{$24(61.5)$} & \multicolumn{2}{|l|}{$20(46.5)$} \\
\hline \multirow{6}{*}{ Learning style preference rankings in descending order, mean (SD) } & 1. Dependent & $3.81(0.75)$ & 1. Independent & $3.68(0.61)$ \\
\hline & 2. Collaborative & $3.65(0.56)$ & 2. Dependent & $3.67(0.86)$ \\
\hline & 3. Participant & $3.52(0.53)$ & 3. Collaborative & $3.63(0.50)$ \\
\hline & 4. Independent & $3.49(0.64)$ & 4. Participant & $3.63(0.48)$ \\
\hline & 5. Avoidant & $2.78(0.44)$ & 5. Avoidant & $2.91(0.42)$ \\
\hline & 6. Competitive & $2.42(0.67)$ & 6. Competitive & $2.20(0.61)$ \\
\hline \multirow{7}{*}{$\begin{array}{l}\text { Learning style preference by age group in descending order (17 - } 21 \text { years), } \\
\text { mean (SD) }\end{array}$} & \multicolumn{2}{|l|}{$n=35$} & \multicolumn{2}{|l|}{$n=40$} \\
\hline & 1. Dependent & $3.84(0.43)$ & 1. Independent & $3.68(0.34)$ \\
\hline & 2. Collaborative & $3.69(0.45)$ & 2. Collaborative & $3.67(0.53)$ \\
\hline & 3. Participant & $3.51(0.51)$ & 3. Dependent & $3.66(0.46)$ \\
\hline & 4. Independent & $3.48(0.41)$ & 4. Participant & $3.63(0.57)$ \\
\hline & 5. Avoidant & $2.82(0.59)$ & 5. Avoidant & $2.90(0.61)$ \\
\hline & 6. Competitive & $2.51(0.74)$ & 6. Competitive & $2.19(0.71)$ \\
\hline Learning style preference by age group in descending order (22 - 28 years), & $n=3$ & & $n=3$ & \\
\hline mean (SD) & 1. Participant & $3.67(0.49)$ & 1. Dependent & $3.83(0.40)$ \\
\hline & 2. Dependent & $3.57(0.25)$ & 2. Independent & $3.67(0.47)$ \\
\hline & 3. Independent & $3.53(0.31)$ & 3. Participant & $3.53(0.38)$ \\
\hline & 4. Collaborative & $3.13(0.45)$ & 4. Collaborative & $3.17(0.32)$ \\
\hline & 5. Competitive & $2.47(0.25)$ & 5. Avoidant & $3.00(0.70)$ \\
\hline & 6. Avoidant & $2.37(0.59)$ & 6. Competitive & $2.33(1.19)$ \\
\hline
\end{tabular}


Table 2. Comparison of means for combined GRLSS score differences and correlations between student groups 1 and 2 and GRLSS norms

\begin{tabular}{|c|c|c|c|c|c|c|c|}
\hline Group pairs & $\begin{array}{l}\text { Mean } \\
\text { difference (SD) }\end{array}$ & $\begin{array}{l}\text { 95\% CI lower, } \\
\text { upper }\end{array}$ & $t$-value & df & $\begin{array}{l}p \text {-value } \\
\text { (2-tailed) }\end{array}$ & Correlation & $p$-value \\
\hline Pair 1: Student groups 1 and 2 (17 - 21 years) & $0.02(0.20)$ & $-0.19,0.23$ & 0.249 & 5 & 0.813 & 0.954 & $0.003^{*}$ \\
\hline Pair 2: Student group 1 and GRLSS norms (17 - 21 years) & $0.11(0.41)$ & $-0.32,0.54$ & 0.651 & 5 & 0.544 & 0.767 & 0.075 \\
\hline Pair 3: Student group 2 and GRLSS norms (17 - 21 years) & $-0.09(0.47)$ & $-0.58,0.40$ & -0.463 & 5 & 0.663 & 0.721 & 0.106 \\
\hline Pair 4: Student groups 1 and 2 ( $22-28$ years) & $-0.13(0.29)$ & $-0.44,0.17$ & -1.112 & 5 & 0.317 & 0.868 & $0.025^{\star *}$ \\
\hline Pair 5: Student group 1 and GRLSS norms (22 - 28 years) & $0.07(0.64)$ & $-0.60,0.74$ & -0.403 & 5 & 0.704 & 0.865 & $0.026^{* *}$ \\
\hline Pair 6: Student group 2 and GRLSS norms (22 - 28 years) & $-0.06(0.39)$ & $-0.47,0.34$ & 0.263 & 5 & 0.803 & 0.560 & 0.247 \\
\hline
\end{tabular}

and constant support. ${ }^{[4]} \mathrm{A}$ student who chooses the independent style learning option is one who is individualistic, confident and acts alone. ${ }^{[4]}$ The younger age group (17 - 21 years) results in both cohorts differed little from the overall results. The least-favoured learning style choices overall were avoidant (group 1: 2.78 (0.67) and group 2: $2.91(0.42)$ ) and competitive (group 1: $2.42(0.67)$ and group 2: $2.20(0.61)$ ). Avoidant-style students are unenthusiastic and disinterested. ${ }^{[4]}$ Competitive-style students are keen to outshine others, be recognised and be rewarded. ${ }^{[4]}$ The top four ranked learning styles were the same in both years, but their order varied (Table 1).

\section{Comparison of learning style mean score differences and correlations between student groups 1 and 2 and Grasha- Riechmann learning style scale norms}

The group means for all six learning styles were calculated. A comparison of learning style means for groups 1 and 2 and the GRLSS norms by student age category are set out in Figs 1 and 2. There is little parity between the GRLSS norms and the scores attained in this study, except in the 17 21-year collaborative category. Collaborative-style students are keen group participants and enjoy sharing ideas. ${ }^{[4]}$

Table 2 illustrates that a statistically significant strong Pearson's correlation was found between the set of learning style means for student groups 1 and 2 (pair 1$)$ in the $17-21$-year age group $(r=0.95 ; p<0.003)$. A significant but weaker correlation between learning style means occurred between student groups in the 22 - 28-year category (pair 4$)(r=0.86$; $p<0.03)$. Paired $t$-tests showed that there was no significant difference in overall GRLSS scores (17 - 21 years) for group 1 (3.3 (0.52)), group $2(3.3(0.62))$ at 0.02 (95\% confidence interval (CI) $-0.19-0.23 ; t(5)=0.249 ; p=0.813)$, or a significant difference in overall GRLSS scores (22 - 28 years) for group 1 (3.1 (0.58)), group $2(3.3(0.55))$ at $-0.13(95 \% \mathrm{CI}-0.44-0.17 ; t(5)=-1.112$; $p=0.317)$. The null hypothesis $\left(\mathrm{H}_{\mathrm{o}}\right)$ put forward was that the GRLSS choices of physiotherapy students in sequential cohorts would be significantly similar. The overall paired $t$-test results were in agreement with the $\mathrm{H}_{0}$. The correlation between student group 1 (22 - 28 years) and the GRLSS norms was significant $(r=0.87 ; p<0.031)$.

\section{Distribution of learning styles by gender}

Fig. 3 illustrates the percentage of students who preferred each learning style by gender, across the two cohorts. It showed that female students had a high preference for the dependent learning style over both years (group 1: $n=12 ; 30.8 \%$ and group $2: n=10 ; 23.3 \%$ ). Male students showed little or no preference for this style. An equal number of female students favoured the participant learning style (group $1: n=8 ; 20.5 \%$ and group $2: n=8 ; 18.6 \%$ ) and the majority of male participants (group 2: $n=6 ; 14.0 \%$ ) also preferred this style. Participant-style students complete coursework, take part in activities and work well with others. ${ }^{[4]}$ Male and female students in group $1(n=5$; $12.8 \%$ ) equally favoured the collaborative style, but differences occurred in group 2, as female participants $(n=9 ; 20.9 \%)$ and male participants $(n=2$; $5.0 \%)$ preferred it. The independent learning style was popular with female group 1 students $(n=5 ; 12.8 \%)$, group 2 students $(n=6 ; 14 \%)$ and male group 2 students $(n=2 ; 4.7 \%)$.

\section{Teaching styles of anatomy lecturers}

The mean age for lecturer group 1 was 33.8 (1.64) years and the ratio of male to female was 3:2. The mean age for lecturer group 2 was 33.7 $(0.58)$ years and the ratio of male to female was 1:2. In 2015, of a total of 5 respondents, 1 lecturer had a $\mathrm{PhD}$ degree (20\%) and 4 lecturers had Master's degrees (80\%). In 2016, of a total of 3 respondents, 2 lecturers had PhDs (66.7\%) and 1 lecturer had a Master's degree (33.3\%). All lecturer group 2 respondents had previously responded to the GRTSS in 2015, as they were also teaching the students in 2015 .

Table 3 records the lecturers' teaching style preferences based on a 5-point Likert scale allocation. Although mean (SD) scores may be higher in one category than in another, the ratings from low to high are based on a comparison with mean scores found by Grasha. ${ }^{[17]} \mathrm{A}$ high rating denotes preference for that teaching style by a respondent. More than one teaching style can be rated highly within a group. Respondents in both groups scored highest for the expert category, where the teacher offers detailed and expert coverage of the work and challenges students to achieve. ${ }^{[15]}$

Grasha $^{[15]}$ described four types of teaching style clusters. Scores rated from highest to lowest for the different style categories on either the GRLSS or the GRTSS, which determined into which cluster the teacher and student should be placed. Table 3 shows that for lecturer group 1 the formal authority-expert and personal models had the highest rating overall. Lecturer group 2 showed highest teaching style preferences for the expert-personal model, facilitator and delegator categories.

The clusters are as follows: cluster 1: student learning styles participant-competitive-dependent; teaching styles - formal authorityexpert. Cluster 2: learning styles - collaborative-participant-dependent; teaching styles - formal authority-personal model-expert. Cluster 3: learning styles - independent-participant-collaborative; teaching styles - expert-facilitator-personal. Cluster 4: learning styles - participantcollaborative-independent; teaching styles - expert-delegator-facilitator.

In lecturer group 1, 3 respondents (60\%) fell into the Grasha cluster 2 and 1 respondent (20\%) into clusters 1 and 4, respectively. In lecturer group 2, 1 respondent (33.3\%) fell into cluster 2 and 2 respondents into cluster 4 . 


\section{Research}

Table 3. Teaching style scores of anatomy lecturer, groups 1 and 2

\begin{tabular}{|c|c|c|c|c|}
\hline Teaching style & Respondent group & Group, mean (SD) & $\begin{array}{l}\text { Mean scores of individual } \\
\text { respondents }\end{array}$ & Rating level \\
\hline \multirow[t]{8}{*}{ Expert } & Lecturer, group 1 & $3.96(0.47)$ & $\mathrm{R} 1=3.8$ & High \\
\hline & & & $\mathrm{R} 2=4.3$ & High \\
\hline & & & $\mathrm{R} 3=4.2$ & High \\
\hline & & & $\mathrm{R} 4=4.3$ & High \\
\hline & & & $\mathrm{R} 5=3.2$ & Moderate \\
\hline & Lecturer, group 2 & $4.37(0.40)$ & $\mathrm{R} 1=4.0$ & High \\
\hline & & & $\mathrm{R} 2=4.8$ & High \\
\hline & & & $\mathrm{R} 3=4.3$ & High \\
\hline \multirow[t]{8}{*}{ Formal authority } & Lecturer, group 1 & $3.52(0.32)$ & $\mathrm{R} 1=3.0$ & Moderate \\
\hline & & & $\mathrm{R} 2=4.0$ & High \\
\hline & & & $\mathrm{R} 3=4.3$ & High \\
\hline & & & $\mathrm{R} 4=2.6$ & Moderate \\
\hline & & & $\mathrm{R} 5=3.7$ & High \\
\hline & Lecturer, group 2 & $3.37(0.76)$ & $\mathrm{R} 1=3.2$ & Moderate \\
\hline & & & $\mathrm{R} 2=4.2$ & High \\
\hline & & & $\mathrm{R} 3=2.7$ & Moderate \\
\hline \multirow[t]{8}{*}{ Personal model } & Lecturer, group 1 & $3.56(0.46)$ & $\mathrm{R} 1=3.3$ & Moderate \\
\hline & & & $\mathrm{R} 2=4.3$ & High \\
\hline & & & $\mathrm{R} 3=3.1$ & Moderate \\
\hline & & & $\mathrm{R} 4=3.3$ & Moderate \\
\hline & & & $\mathrm{R} 5=3.6$ & High \\
\hline & Lecturer, group 2 & $3.70(0.98)$ & $\mathrm{R} 1=4.0$ & High \\
\hline & & & $\mathrm{R} 2=4.5$ & High \\
\hline & & & $\mathrm{R} 3=2.6$ & Low \\
\hline \multirow[t]{8}{*}{ Facilitator } & Lecturer, group 1 & $3.43(0.53)$ & $\mathrm{R} 1=4.0$ & Moderate \\
\hline & & & $\mathrm{R} 2=3.7$ & Moderate \\
\hline & & & $\mathrm{R} 3=3.2$ & Moderate \\
\hline & & & $\mathrm{R} 4=2.9$ & Low \\
\hline & & & $\mathrm{R} 5=2.8$ & Low \\
\hline & Lecturer, group 2 & $3.87(0.51)$ & $\mathrm{R} 1=4.3$ & High \\
\hline & & & $\mathrm{R} 2=4.0$ & High \\
\hline & & & $\mathrm{R} 3=3.3$ & Moderate \\
\hline \multirow[t]{8}{*}{ Delegator } & Lecturer, group 1 & $2.68(0.39)$ & $\mathrm{R} 1=2.7$ & Moderate \\
\hline & & & $\mathrm{R} 2=3.0$ & High \\
\hline & & & $\mathrm{R} 3=2.5$ & Moderate \\
\hline & & & $\mathrm{R} 4=2.4$ & Moderate \\
\hline & & & $\mathrm{R} 5=2.2$ & Moderate \\
\hline & Lecturer, group 2 & $3.05(0.07)$ & $\mathrm{R} 1=3.1$ & High \\
\hline & & & $\mathrm{R} 2=3.0$ & High \\
\hline & & & $\mathrm{R} 3=2.1$ & Moderate \\
\hline
\end{tabular}

Using the cluster combinations listed above, it was seen that in 2015, where the top three ranked learning styles chosen were dependent, participant and collaborative, the most appropriate teaching style cluster would be cluster 2 . In that year, $60 \%$ of faculty subscribed to cluster 2 . Other lecturers were in clusters 1 and 4 and would be able to relate to 2 of 3 of the most preferred learning styles. In 2016, the top three ranked learning styles were independent, dependent and collaborative. It was apparent that in 2016, 1 of the lecturer participants had 'accommodated' from cluster 1 or 2 to cluster 4 . This meant that 2 of the lecturers had now aligned themselves with the teaching styles represented in cluster 4 and therefore would facilitate and delegate in their teaching methodology. This would be more in line with the more independently orientated student group 2 .

\section{Discussion}

In the overall scenario, age influenced student learning style preferences. Marked preferential differences were seen between the 17 -21-year age cohorts and the related 22 - 28-year age cohorts. A comparison of the means for the two groups for 2015 and 2016 showed more compatibility between the younger age groups (50\%) than the older age groups (17\%) Life experience and environmental factors may have influenced diversity in older students' thinking. ${ }^{[18]}$ Overall student participants were millennials from generation Y, born between 1982 and 2003, which might have played a part in age-related learning style preference. Coates ${ }^{[19]}$ describes children of the millennial generation as being mollycoddled by their parents and unable to make decisions or manage conflict. Hence, these students possibly lack 
independence and are more suited to the Grasha dependent style category seen to dominate learning style preference in the 2015 student cohort. The 2016 student cohort's preference for the independent learning style may appear to contradict this assumption, but consideration should be given to the result being marginal, with the dependent style ranked as a close second preference.

Gender has been shown to influence learning style preference. ${ }^{[20]}$ Gender considerations impacted results of this study, with some clear differences between male and female learning style preferences. While both female student cohorts clearly ranked the dependent learning style highly, male students did not. Furthermore, the predominantly female nature of both student cohorts skewed the overall learning style preference towards the dependent category, especially in 2015. However, this may not be problematic, as Kulac et al. ${ }^{[21]}$ found that female medical students preferring the dependent style scored higher than their male counterparts in examinations. Unpopularity of the avoidant and competitive categories was seen across all genders in both cohorts, which could be considered a similarity between gender preferences. Using the participant, collaborative and independent learning style markers for guidance, most gender style preference alignment was in the collaborative category in 2015, but in the participant category in 2016. The collaborative category is associated with the desired deep-learning approach that produces better academic results. ${ }^{[20]}$ Hence, the prominence of the selection of the collaborative learning style in both female groups and male group 1 may augur well for beneficial outcomes in these groups.

It has also been postulated that different learning styles pertain to specific student groups. ${ }^{[10,15]}$ Based on the evidence, the learning styles of medically orientated student bodies appear to coalesce and are dissimilar to other student group preferences. ${ }^{[16]}$ This study aimed to assess whether physiotherapy students favoured particular learning styles. It was shown that while the order of preference differed over the 2 years, there was consistency in the first four listed preferences. Furthermore, the collaborative category was similarly selected according to mean scores for both years. However, to address the diversity of learning styles possible in student groups, more accurate diagnostics may be achieved from more than one learning style instrument being used in this type of research. ${ }^{[22]}$

The 2015 and 2016 GRTSS survey results showed characteristic cluster groupings of lecturers' styles. ${ }^{[15]}$ It can be challenging for faculty to match learning styles of specific student populations to teaching styles to ensure clinical readiness. ${ }^{[23]}$ In 2011, King ${ }^{[2]}$ stated that the teaching/learning process is less effective if there is no cohesion between the teaching style of the teacher and learning style of the student. Furthermore, anxiety levels are lowered and the degree of learning and teaching satisfaction is increased when the learning styles of students and the teaching styles of staff are matched appropriately. ${ }^{[12]}$ The results of this study showed a degree of cohesion between the learning styles of 2 student cohorts surveyed in 2015 and 2016 and the respective teaching styles of their lecturers. This is in line with Grasha's ${ }^{[16]}$ suggestion that teachers vary their teaching style to accommodate the multiplicity of student learning styles, as such compatibility would augur well for establishing a sustained learning environment in future. ${ }^{[15]}$

\section{Study strengths and limitations}

With regard to the strengths of the study, although the study samples were small and limited to the same institution, data were collected from two sequential student and staff cohorts. The significantly strong positive correlation of results between samples for the 17 - 21-year age cohorts and the 22 - 28-year age cohorts meant the two samples could be pooled, leading to more valid and reliable conclusions being made. There was a high response rate for the student cohorts each year. Lecturer groups were small and the response was not favourable in 2016. However, it was apparent that in 2016, 1 respondent who had also participated in 2015 'accommodated' to a different teaching style cluster more in line with student group 2 learning requirements, adding a new dimension to the results. A weakness was that there was paucity of information in the literature for comparison of GRLSS findings with regard to student groups' learning styles; therefore, comparisons had to be drawn with studies using other learning style instruments for data collection. This process was akin to matching 'apples' with 'pears' - an unsatisfactory situation. Furthermore, since the data were collected for this study, the movement debating the learning style 'myth' has gathered momentum, with researchers noting that moves towards 'debunking' such data collection are not necessarily effective, but suggesting that there should be a progression towards evidence-based research in its place. $^{[25]}$

\section{Conclusion}

This study gives insight into the possible learning styles of physiotherapy students as applied to the anatomy scenario. It is therefore useful for faculty involved in gross anatomy education of this student population to consider the outcomes to perhaps adapt their teaching styles to facilitate beneficial outcomes for their students. However, the question remains whether this study is sufficient to evaluate the learning styles of physiotherapy students in anatomy definitively - generally and in particular - in relation to age and gender considerations. A larger longitudinal study may provide answers to this question and give new direction to gross anatomy learning for this student population. However, there is an ongoing debate as to whether continued use of learning style instruments is valid, and although this study did produce some plausible findings, consideration has to be given to conducting the suggested longitudinal research using more verifiable evidence-based research methodology.

Declaration. This study was undertaken and published as part of the PhD degree requirements of the first author.

Acknowledgements. We wish to acknowledge the willing involvement of the participants.

Author contributions. All authors were involved in the study design. The first author was responsible for data collection, statistical analysis of the data, writing the drafts and for submission and re-submission of the article. All authors reviewed the drafts before they were submitted or resubmitted for publication.

Funding. South African Society of Physiotherapy Research Foundation (grant no. RC2016/01/03).

Conflicts of interest. None.

\footnotetext{
1. Shead D, Roos R, Olivier B, et al. Gross anatomy curricula and pedagogical approaches for undergraduate physiotherapy students: A scoping review protocol. JBI Database System Rev Implement Rep 2016;14(10):98-104 https://doi.org/10.11124/JBISRIR-2016-003164

2. Claxton CS, Rolston Y. Learning Styles: Their Impact on Teaching and Administration. 1st ed. Washington, DC American Association for Higher Education, 1978.

3. Cassidy S. Learning styles: An overview of theories, models and measures. Educ Psychol 2004;24(4):419-444 https://doi.org/10.1080/0144341042000228834

4. Rollins M. Learning style diagnostics: The Grasha-Riechmann student learning styles scale. 2015. http://www. elearningindustry.com/learning-style/ (accessed 1 March 2017).

Fleming ND. The case against learning styles: 'There is no evidence ... '2012. http://vark-learn.com/wp-content/ uploads/2014/08/The-Case-Against-Learning-Styles.pdf (accessed 27 April 2018).
} 
6. Pashler H, McDaniel MA, Rohrer D, Bjork R. Learning styles: Concepts and evidence. Psychol Sci Public Interest 2008;9(3):105-119. https://doi.org/10.1111/j.1539-6053.2009.01038.x

7. Willingham DT, Hughes EM, Dobolyi DG. The scientific status of learning style theories. Teach Psycho 2015;42(3):266-271.

8. Husmann PR, O'Loughlin VD. Another nail in the coffin for learning styles? Disparities among undergraduate anatomy students' study strategies, class performance, and reported VARK learning styles. Anat Sci Educ 2018; (epub ahead of print). https://doi.org/10.1002/ase.1777

9. Grasha AF, Yangarber-Hicks N. Integrating teaching styles and learning styles with instructional technology. Coll Teach 2000;48(1):2-11. https://doi.org/10.1080/87567550009596080

10. Kolb DA. Experiential Learning. 1st ed. Englewood Cliffs, NJ: Prentice-Hall, 1984.

1. Spoon JC, Schell JW. Aligning student learning styles with instructor teaching styles. J Industr Teach Educ 1998:35(2).

12. Curry A. An organization of learning styles theory and constructs. Am Educ Res Ass 1983:1-25.

13. Grasha AF, Riechmann-Hruska S. Grasha-Riechmann teaching style scale (GRTSS). 1996. http://www.longleaf. net/teachingstyle.html (accessed 9 October 2018).

4. Mohammadi S, Mobarhan MG, Mohammadi M, Ferns GAA. Age and gender as determinants of learning style among medical students. Br J Med Med Res 2015;7(4):292-298.

15. Grasha AF. Teaching With Style: A Practical Guide to Enhancing Learning by Understanding Teaching and Learning Styles. 2nd ed. San Bernadino, CA: Alliance, 2002.

16. Baykul Y, Gürsel M, Sulak H, et al. A validity and reliability study of Grasha-Riechmann learning style scale. In J Educ Pedagog Sci 2010;4(3):323-330.
17. Alami M, Ivaturi P. Typical teaching styles among ELC lecturers at Salalah College of technology, Oman. J App Ling Lang Res 2016;3(7):251-261.

18. Smith DM, Kolb DA. User's Guide for the Learning-Style Inventory. 1st ed. Boston, MA: McBer, 1986

19. Coates J. Generational Learning Styles. 1st ed. River Falls: LERN Books, 2007.

20. Azarkhordad F, Mehdinezhad V. Explaining the students' learning styles based on Grasha-Riechmann's student learning styles. J Admin Manage Train 2016;12(6):241-247.

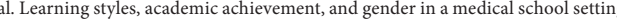
J Clin Anal Med 2015;6(5):608-611. https://doi.org/10.4328/JCAM.2317

2. Hawk TF, Shah AJ. Using learning style instruments to enhance student learning. Decis Sci J Innov Educ 2007;5(1):1-19.

23. Meehan-Andrews TA. Teaching mode efficiency and learning preferences of first year nursing students. Nurs Educ Today 2009;29(1):24-32. https://doi.org/10.1016/j.nedt.2008.06.007

24. King A Culture learning and development: A case study on the Ethiopian higher education system. High Ed Res Net J 2011;4:5-13

25. Newton PM, Miah M. Evidence-based higher education - is the learning styles 'myth' important? Front Psychol 2017;8:444. https:///doi.org/10.3389/fpsyg.2017.00444

Accepted 31 May 2018. 